\title{
STOCHASTIC MODELLING OF CASH FLOW FOR PERSONAL INSURANCE FUND USING THE CLOUD DATA STORAGE
}

\author{
Kseniia Bazilevych 1), Mary Mazorchuk 1), Yurii Parfeniuk 2), Viktoriia Dobriak 1), \\ levgen Meniailov ${ }^{1)}$, Dmytro Chumachenko ${ }^{1)}$
1) National Aerospace University - National Aerospace University, 17 Chkalov str., Kharkiv, 61070, Ukraine, ksenia.bazilevich@gmail.com,mazorchuk.mary@gmail.com, viktoriya.dobryak@gmail.com, evgeniimenyailov@gmail.com, dichumachenko@gmail.com
2) National Technical University "Kharkiv Polytechnic Institute", 2 Kyrpychova str., Kharkiv, 61002, Ukraine, parfuriy.1@gmail.com

Paper history:

Received 17 July 2017

Received in revised form 09 July 2018

Accepted 20 September 2018

Available online 30 September 2018

\section{Keywords:}

insurance cash flow model;

actuarial valuation;

contextual characteristics;

stochastic uncertainty;

logistic regression;

Monte Carlo simulation.

\begin{abstract}
In this paper the model and applied information system are proposed for modelling cash flow of insurance funds with use cloud data storage. Cash flow valuation is performed taking into account contextual characteristics of an insured under conditions of stochastic uncertainty. The proposed insurance cash flow model of the financial fund of insurance company allow to account the financial solvency probability based on the analysis of contextual properties of insureds, that increase the estimation accuracy of the modeling cash flows. Also, the model takes into account insurance bonus non-payment during the insurance company operation. In this paper, we propose a structure of an informational system, which is called "Insurance Life". This system supports downloading and uploading data with the cloud service pCloud according to safety requirements of data. The main results of the research are introduced into practice of the operation of insurance companies in forms of software applications and results of calculations.
\end{abstract}

Copyright $(\mathbb{C}$ Research Institute for Intelligent Computer Systems, 2018. All rights reserved.

\section{INTRODUCTION}

Personal insurance is a security that is essential when a person losses labour capability, aggravated health or death. Informational flow in the field of personal insurance is extensional, heterogeneous, and connected to the accidental nature of the insurance events [1-5]. Today it is impossible to control huge cash flows of the insurance companies without information technologies (IT), ability to forecast and analyse data and safe data storage. A small percent of the insurance companies employ specialized systems (Ukrainian or foreign), that are either too expensive or do not provide the solutions for all of the necessary tasks [6-8]. Thus, these systems cannot be used for the modelling or storing and updating data, or provide only accounting functions and document management.

Systems mostly do not enable modelling the risks and conducting the actuarial estimation that proves to be effective mathematical setter for cash flows of the insurance funds. This research is up to date, as there is no integrated approach that allows modeling the cash flow of the insurance funds in complex, not by parts, especially when it goes about the condition of uncertainty [9].

The term uncertainty describes a situation with unknown information and arises in numerous fields, including insurance, philosophy, physics, statistics, economics, etc. There are many authors, who studied the problems of uncertainty. According to E. Kuzmin [10] term uncertainty can be considered as 1) information measure; 2) possibility to choose the alternatives and variability of choice 3 ) source of risk 4) event instance uncertainty. Frank H. Knight [11] is commonly credited with defining the distinction between decisions under "risk" (known chance) and decisions under "uncertainty" (unmeasurable probability). Also in the beginning terms such as risk, disaster, indeterminacy and uncertainty are discussed in detail in book of 
D. Proske [12]. Decision making in the condition of crisis and manage risks are described in work of V. Glushenko [13].

F. Knight defines the risk as an uncertainty that can be measured. In terms of research, risk appears when quantifying cash flow if the amount of insolvent insured and amount of payments of claims are not considered. It can be defined by changing the values of the model key parameters (which may be caused by the factors of unknown nature).

The main factors that cause uncertainty in the research subject area are the number of insurance cases and the insureds solvency (research sets probability distribution for both factors). Thus, we consider stochastic uncertainty. According to O. Ventstel "unknown factors are random values, stochastic values of which are known or can be received" [14]. Stochastic uncertainty causes multiple results that can be further analysed using probability theory (for example with law of average and expectation functions).

Today, insurers must build an average customer model for each product, otherwise insurance plan, and work at all cannot be planned. Building this model requires constant analysis of personal data. To reduce the mistakes when modelling financial flow, the data about insureds must be considered. An important stage to process these data is analysis of the contextual characteristics that influence financial flow [15], when influence of every characteristic on solvency is estimated.

Also, we have to design the model of insurance fund. Paper [16-18] demonstrates the consistency of action of quantifying the cash flow for insurance funds. We used these approaches in our study.

To solve these issues, we suggest to use mathematical modelling and software with support for cloud technologies suitable for keeping personal data safe. We should note, that in Ukraine, cloud technologies have not reached potential in field of personal insurance comparing to other fields yet. That is caused partly by the fact that insurance companies use outdated systems of data processing, and reorientation to work with cloud services will take time. However, now situation changes. Recent publications [19-21] supports the view that insurers find the use of cloud software as advantageous.

Today $48 \%$ of companies use cloud services. According to researchers from the IDC [22] company, this percentage is going to increase to $90 \%$ in the short term.

Cloud software meets the demand of flexibility, speed, and scale, allows speeding the response for changes and optimizing the data processing.

Purpose of the study is to develop a model of the cash flow of personal insurance funds in conditions of stochastic uncertainty and with software that access and update information about insureds by means of cloud services. It will allow us to automate the processing of data and determine insurance amount, needed to assess the cash flow with minimization damage for the insurance fund.

\section{CASH FLOW AND FINANCIAL CONDITION OF THE PERSONAL INSURANCE FUND}

The financial condition of the personal insurance fund can be defined as a condition of the internal cash flow of the fund at the moment of actuarial valuation, that takes a place when providing premiums and payments (Fig.1).

In the diagram (Fig.2), it can see the formalized subject area of the formation the personal insurance fund. The diagram provides the following keys $p_{1}+p_{2}+\ldots+p_{N}=\sum_{z=1}^{N} p_{Z}-$ premiums that arrive on the contracts $N ; z$-a single insurance contract; $b_{1}+b_{2}+\ldots+b_{v}=\sum_{j=1}^{v} b_{j}-$ payments on the contracts that led to the insurance events; $v$ - amount of the insurance events; $j$-single insurance event.

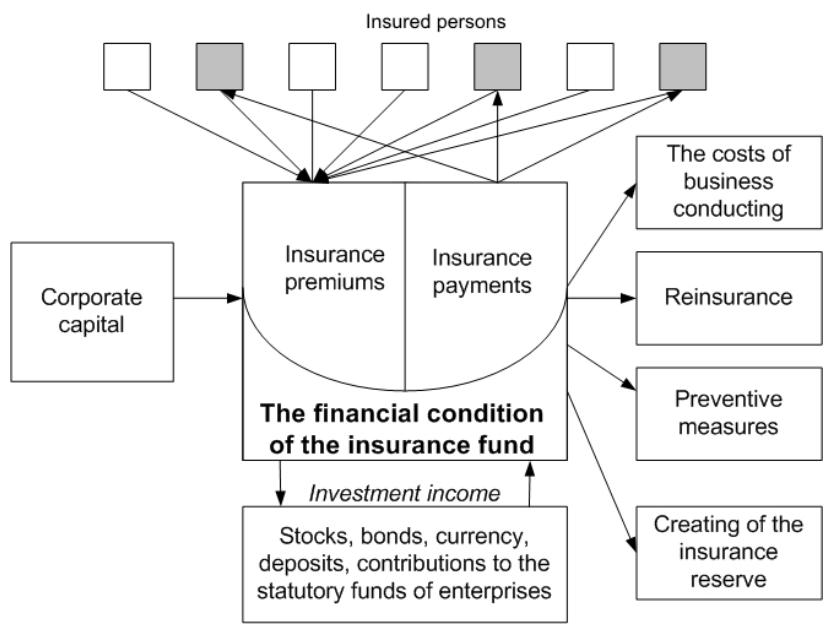

Figure 1 - Diagram of the formation of the personal insurance fund's financial condition

Fig. 2 provides the factors influencing the insurance process and insurance fund condition.

The factors influencing the formation of the personal insurance fund are the factors that influence numeric characteristics of the insurance fund cash flow.

The external factors influencing the formation of the personal insurance funds are financial and biomedical.

Biomedical factors are given as $Y=\left\{y_{\text {ind }}\right\}$, where ind $\in \overline{1, \text { Biom }}$, Biom - the number of biomedical factors. Biometrical factors are the data 
on the aging dynamics (people death-rate), given as $O=\left\{o_{i g}, \forall o_{i g} \geq 0\right\}, \quad o_{i g}-$ the death probability according to the $i$-age and $g$-characteristic, $O \subset Y$; data on the people health status, provided in form of $S=\left\{s_{m k}, \forall s_{m k} \geq 0\right\}$, where $s_{m k}$ probability of having a disease, according to the statistics of the $m$-year and $k$-disease class, $S \subset Y$.

Financial factors are investments income and inflation that are considered when carrying out the long term insurance. In addition, when analyzing the influential factors we defined the number of the contextual characteristics of the insured.

These characteristics reflect a particular context, unique to a particular group, community, society and individual.

In this study contextual characteristics are gender, education, incomes and other. Insurance company can determine their own characteristics, based on data that is available for modelling.

In the complex, contextual characteristics influence the insureds solvency, which we suggest in form of matrix [6]:

$$
C=\left[\begin{array}{cccc}
C_{11} & C_{12} & \ldots & C_{1 \theta} \\
C_{21} & C_{22} & \ldots & C_{2 \theta} \\
\ldots & \ldots & \ldots & \ldots \\
C_{N 1} & C_{N 2} & \ldots & C_{N \theta}
\end{array}\right],
$$

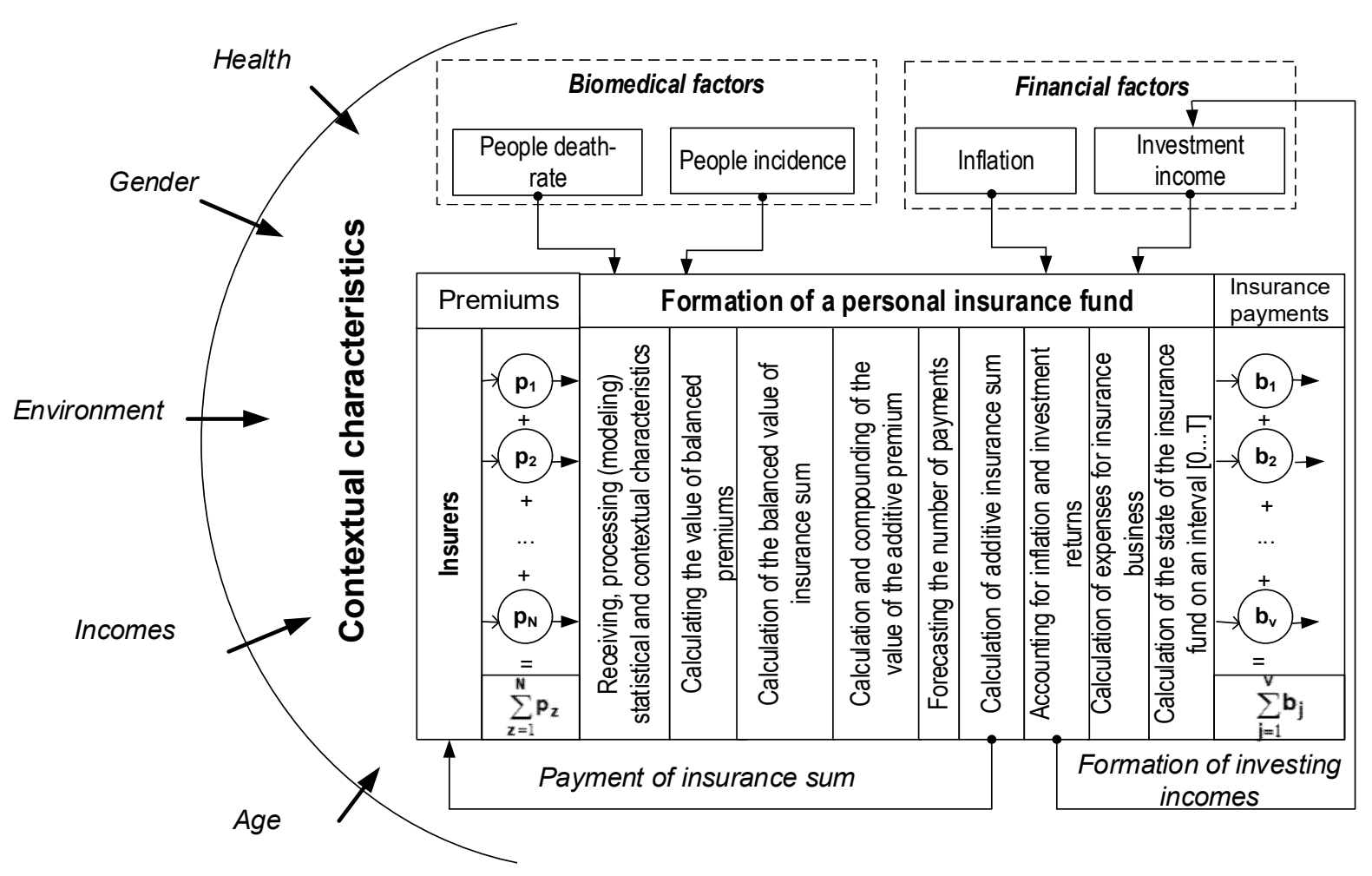

where $N-$ is the number of insureds (the number of those that are insured by a single company), $\theta$ - the number of the contextual characteristics, $C_{z \text { ins }}-$ value of the influencing factor from the $\mathrm{C}$ matrix for the insured $\mathrm{z}$, that can be measured by means of a scale, $z \in\{1,2, . ., N\}$, ins $\in\{1,2, . ., \theta\}$.

In order to account for the influence of the single factors on the insureds solvency we used the model of the logistic regression.

The probability that the initial variable $y=1$ for the given value of the explanatory variable $C$ will be equal to $\mathrm{P}(\mathrm{y}=1 \mid C)=\rho(C)$, and the probability that $y=0$ at the given value $C$, will be equal to $\mathrm{P}(\mathrm{y}=0 \mid C)=1-\rho(C)$.

The conditional value for logistic regression in this case is determined by the formula

$$
\rho(C)=\frac{\mathrm{e}^{\beta_{0}+\sum_{i=1}^{\theta} \beta_{i} \cdot C}}{1+\mathrm{e}^{\beta_{0}+\sum_{i=1}^{\theta} \beta_{i} \cdot C}},
$$

where $C$ - an explanatory variable, $\beta_{0}, \beta_{1}, \ldots, \beta_{\theta}-$ parameters to find (regression coefficients), $\rho(C)-$ probability of the event.

We estimated the regression coefficients by method of maximum likelihood estimation.

Figure 2 - Diagram of the cash flow of the personal insurance fund and the factors influencing 
This work described data collection of insurer (150 persons). Representativeness error is not more than $8 \%$. Stratified method of data collection is used.

We described the contents, structure, and layout of a data collection. This research employed a binary variable, default insurer payment $(\mathrm{Yes}=1, \mathrm{No}=0)$, as the response variable. This study used the following 8 variables as explanatory variables: Age (year), Gender ( 1 = male; 2 = female), Residence permits (year), Profession risk $(1=$ high, 2 =medium,$\quad 3=$ low $), \quad$ Workplace $\quad(1=$ public institution, 2 = commercial enterprise), Seniority (year), Ownership of Checking account $(1=$ yes, $2=$ no), Home ownership $(1=$ yes, $2=$ no). We used dataset from insurance company (without personal information).

When building a model, we estimated the statistical significance of the separate factors.

As a result, we received the values for the probabilities for each of insureds to get to the Solvent or Insolvent category depending on the different input data. In the long term, classification on solvency allows minimizing the risk of nonpaying the insurance premiums in individual contracts and obtaining an adjusted estimate of the number of insurance contracts.

Consider the parameters of the logistical equation for the given task and find the possibility for the insured to provide a premium to estimate his solvency. The function is defined on the infinite interval and takes values in the range from 0 to 1 . We have to find the best estimates of the parameters. The threshold of insolvency of insureds determined by the expert (and on the insurer's inclination to take risks).

\section{MODEL OF THE CASH FLOW OF THE PERSONAL INSURANCE FUND AT THE STOCHASTIC UNCERTAINTY}

It is difficult to overestimate the importance of modeling for the systems in different subject areas. The fundamental work on system modelling belongs to V.M. Tomashevsky [23]. In his work author, considers the system used for the study as a model. Webster's Dictionary defines the model as "a simplified description of a complex phenomenon or process."

This study suggests modelling of cash flow to consider the specifics of the personal insurance fund cash flow formation process. The study sets the following aims:

- to conduct a long-term analysis of the formation of cash flows of the personal insurance fund for specified of factors influencing values for the possibility to correct the input values of the factors influencing and to analyse the dynamics of the cash flows of the personal insurance fund formation;

- to support the decision of the decision maker when formatting of cash flows of the personal insurance fund in conditions of stochastic uncertainty.

The input data for the model, that is $i^{\prime}$ - interest rate, $i^{\prime \prime}$ - indexation index, $t$ - initial moment of modeling, $F_{t}$ - cash flows of the personal insurance fund condition at the initial moment of the actuarial valuation $t, T$ - the final moment of actuarial valuation, $\quad N$ - total number of contracts, $b_{Z}-$ insurance payment for each insurance contract $z$, $f_{Z}-$ the costs of insurance for each contract, $\operatorname{Lim}_{\text {liq }}$ - adoption level of insolvency of insureds. The $F_{t}$ is modelled as a condition of the cash flows of the personal insurance fund at the final moment of the actuarial valuation.

The model is based on the following assumptions: $t \in\{1,2, . ., T-1\}$ - discrete time with a discretization interval equal to a year; $t=T$ - the final point when the assessment of the cash flow of the personal insurance fund is conducted; $y \in\{t, t+1, . ., T\}-$ moments of actuarial valuation from moment $t$ to moment $T ; z \in\{1,2, . ., N\}-$ numbers of the insurance contracts in the insurance portfolio; $\rho(C)_{Z}$ value determines solvency of the insured in the contract $z$, where $C-$ is an explanatory variable; $v_{y}$ - value determines the number of insurance events at the moment $y$, and the value $\sum_{k=1}^{v_{y}} \sum_{y=t}^{T} b_{k y}$ - additive value of payments under contracts for all moments of actuarial valuations including $T$.

The obtained values allow us consider the number of contracts to be payed, as well as the total number of payments at each stage of modeling. Premiums and payments are made on each stage of actuarial valuation.

Cash flow of the personal insurance fund at the moment $T$ is provided as $F_{T}$ :

$$
\begin{aligned}
& \mathrm{F}_{T}=\mathrm{F}_{t} \cdot\left(1+i^{\prime}\right)^{T-t}+ \\
& +\sum_{y=t}^{T} \sum_{z=1}^{N} p_{z y} \cdot\left(1+i^{\prime}\right)^{T-y}-\sum_{y=t}^{T} \sum_{k=1}^{v_{y}} b_{k y} \cdot\left(1+i^{\prime \prime}\right)^{y},
\end{aligned}
$$

where $\sum_{y=t}^{T} \sum_{z=1}^{N} p_{z y} \cdot\left(1+i^{\prime}\right)^{T-y}-$ is additive value of 
the $p_{Z}$ premiums on each contract $z$ for all times of the actuarial valuation $y$ to the $T$ moment, considering the time factor, $N$ - the number of insureds, $\sum_{y=t}^{T} \sum_{k=1}^{v_{y}} b_{k y} \cdot\left(1+i^{\prime \prime}\right)^{y}-$ additive value of payments $b_{k} \quad$ for all the contracts $k$ where insurance event occurred, for all the times of actuarial valuations $y$ to the moment $T$ considering the time factor.

The values $\sum_{y=t}^{T} \sum_{k=1}^{v_{y}} b_{k y} \cdot\left(1+i^{\prime \prime}\right)^{y}$ and $v_{y}$ are calculated using the method of evaluation of the insurance events based on the analysis of probability characteristics [24].

This method assumes that payments of the insurance company are distributed according to the Poisson (for life insurance and pension insurance) or according to the negative binomial law (in the case of health insurance). It enables receiving the number of insured events that occurred before the moment with known age $x$ in each contract or if statistics is available for the last period. Calculation of the premium $p_{Z}$ for each insurance contract is based on the amount of payment $b_{Z}$, and depends on the type and term of the insurance chosen.

In order to find the insured solvency in the model there are a few methods that depend on the insurance company policy and the type of the insurance.

1. Insurance contracts are not concluded with the insolvent insured. In this case, instead of $N$ we will use $N-N_{i}$ where $N_{i}$-is the number of contracts concluded with insolvent insured (i.e. the insured $\rho(C)_{Z}<\operatorname{Lim}_{\text {liq }}$ where $\operatorname{Lim}_{\text {liq }}-$ is acceptable level of insolvency);

2. Insurance contracts are concluded with insolvent insured, and in absence of payments, the following formula is used:

$$
\begin{aligned}
& \mathrm{F}_{T}=\mathrm{F}_{t} \cdot\left(1+i^{\prime}\right)^{T-t}+ \\
& +\sum_{y=t}^{T} \sum_{z=1}^{N_{y}} p_{z y} \cdot\left(1+i^{\prime}\right)^{T-y}-, \\
& -\sum_{y=t}^{T} \sum_{k=1}^{v_{y}} b_{k y} \cdot\left(1+i^{\prime \prime}\right)^{y}-\Delta
\end{aligned}
$$

where $N_{y}$ - is the number of contracts concluded with insolvent insured, insurance payments for insolvent insured $b_{k_{i} y}=0$, variable $\Delta$ can have different values depending on the insurer's purpose: a) insurance premiums are compensated in full

$$
\Delta=\sum_{y=t}^{T} \sum_{n=1}^{N_{i_{y}}} p_{n y} \cdot(y-1) \text {. }
$$

Then, $N_{i_{y}}$ - the number of insolvent insured at the moment of actuarial valuation $y$;

b) insurance premiums are offset by deduction of insurance costs $-f_{n}$ :

$$
\Delta=\sum_{y=t}^{T} \sum_{n=1}^{N_{i_{y}}}\left[p_{n y} \cdot(y-1)\right] \cdot\left(1-f_{n}\right)
$$

c) insurer pays the redemption amount $S_{n}$ to insureds according to the contracts of insolvent insureds provided by the insurance contract and by the law about insurance in Ukraine:

$$
\Delta=\sum_{y=t}^{T} \sum_{n=1}^{N_{i_{y}}} S_{n y},
$$

where $\sum_{y=t}^{T} \sum_{n=1}^{N_{i_{y}}} S_{n y}$ - additive value $N_{i_{y}}$ of the on insolvent insureds at all times of actuarial valuations $y$ including $T$.

\section{EXPERIMENTS AND RESULTS OF THE MODELING}

When implementing the developed model, it becomes obvious that to prove adequacy of a model we need to perform a series of tests using the formula (4). For that, we used the Monte Carlo simulation.

The main task is to calculate the value of the cash flow of the personal insurance fund at the time of the actuarial valuation. In this case, we choose a random value $F_{T}$, the mathematical expectation of which is equal to $M\left(F_{T}\right)=X$. We perform $Q$ tests, receive $Q$ possible values for the $F_{T}$ variable and calculate the arithmetic mean $\bar{F}_{T}$ We consider $X^{*}$ estimate to be $\bar{F}_{T}: X \approx X^{*}=\overline{F_{T}}$.

For modelling cash flow, we developed the "Insurance Life" system, designed by using .NET technology, based on model of the cash flow, which has been presented above. The results are provided in Table 1. 
Table 1. The results of the insurance fund and insurance events modeling by means of "Insurance Life" system, 8590 tests, 6 moments of estimation.

\begin{tabular}{|c|c|c|c|c|c|c|c|}
\hline$T$ & $v_{d 1 T}$ & $v_{d 2 T}$ & $v_{d 3 T}$ & $v_{d 4 T}$ & $v_{d T}$ & $v_{S T}$ & $\bar{F}_{T}$ \\
\hline 0 & 0 & 0 & 0 & 0 & 0 & 0 & 10493697.58 \\
\hline 1 & 1 & 3 & 5 & 9 & 18 & 0 & 11132763.76 \\
\hline 2 & 1 & 3 & 6 & 10 & 20 & 177 & 10933502.26 \\
\hline 3 & 1 & 3 & 6 & 9 & 19 & 165 & 10714981.25 \\
\hline 4 & 1 & 3 & 6 & 8 & 18 & 167 & 10532287.59 \\
\hline 5 & 1 & 3 & 6 & 6 & 17 & 154 & 10382836.10 \\
\hline
\end{tabular}

Table 2. The results of the insurance fund and insurance events modeling by means of "Insurance Life" system, 8590 tests, 6 moments of estimation.

\begin{tabular}{|c|c|c|c|c|c|c|}
\hline$T$ & $\sigma_{x}$ & $\begin{array}{c}\text { Percentage } \\
\text { rate } \varepsilon \text { to } \bar{F}_{t}\end{array}$ & $\frac{\varepsilon \sqrt{Q}}{\sigma_{x}}$ & $2 \hat{O}\left(\frac{\varepsilon \sqrt{Q}}{\sigma_{x}}\right)$ & $\left(\frac{\sigma_{x}}{\varepsilon}\right)^{2}$ & $Q$ \\
\hline 0 & 388215.94 & 0.09 & 2.30 & 0.9786 & 1507.12 & 5787 \\
\hline 1 & 411858.29 & 0.09 & 2.17 & 0.9707 & 1696.27 & 6514 \\
\hline 2 & 434590.82 & 0.09 & 2.05 & 0.9606 & 1888.69 & 7253 \\
\hline 3 & 444466.71 & 0.09 & 2.01 & 0.9545 & 1975.51 & 7586 \\
\hline 4 & 462422.88 & 0.09 & 1.94 & 0.9464 & 2138.35 & 8211 \\
\hline 5 & 472955.54 & 0.1 & 1.89 & 0.9412 & 2236.87 & 8590 \\
\hline
\end{tabular}

The accuracy of the determination of the mathematical expectation by the arithmetic mean was obtained from the formula

$$
P\left(\left|\overline{F_{T}}-X\right|<\varepsilon\right)=2 \hat{O}\left(\frac{\varepsilon \sqrt{Q}}{\sigma_{x}}\right),
$$

where $\hat{O}-$ is the Laplace function, $\varepsilon-$ is the permissible deviation, $\sigma_{x}=\sqrt{\frac{1}{Q} \sum_{i=1}^{Q} F_{T i}{ }^{2}-{\overline{F_{T}}}^{2}}$ is the statistical estimate of the variance obtained from the series of tests.

Table 2 confirms that the results obtained with the model are adequate. In this case, the tolerance $\varepsilon=10000(U A H)$, do not exceed $10 \%$ value of the insurance fund.

For each moment of actuarial evaluation, we calculated the required number of tests by formula

$$
Q=\left(\frac{\sigma_{x}}{\varepsilon}\right)^{2}\left[\hat{O}^{-1}\left(\frac{1}{2} H\right)\right]^{2},
$$

where $\hat{O}^{-1}-$ is the inverse Laplace function. The level of confidence was $H=0.95$, according to the requirements of Solvency II. Due to the fact that different evaluation moments require different number of tests we set the maximum value for all the tests, equal to $Q=8590$. In order to verify the adequacy of a mathematical model, two criteria must be fulfilled: accuracy and consistency. Accuracy in this case can be measured by a generalized characteristic of the incoherence of the cash flows of the personal insurance fund model (mathematical expectation) and the arithmetic mean with a given confidence probability.

From Table 2, we can see that the coincidence of the mathematical expectation and the arithmetic mean probability is equal to 1 , that proves the positive results obtained from the simulation. For each moment of actuarial evaluation, the required number of tests was calculated. Because different evaluation points require different number of tests, the maximum number of tests $(Q=8590)$ was chosen as the total number of system tests.

Figure 3 demonstrates a graphical display of the results of the cash flows of the personal insurance fund modelling. Results of pessimistic, optimistic and most probable scenarios are present on graphic.

Consistency of modeling results is confirmed by the logic and validity of using the mathematical models and methods complex, and the correspondence of the obtained and expected results with a given probability. When testing the model, the following results were obtained: $67 \%$ of the data practically coincide with expert estimates, $33 \%$ are close to these estimates. 


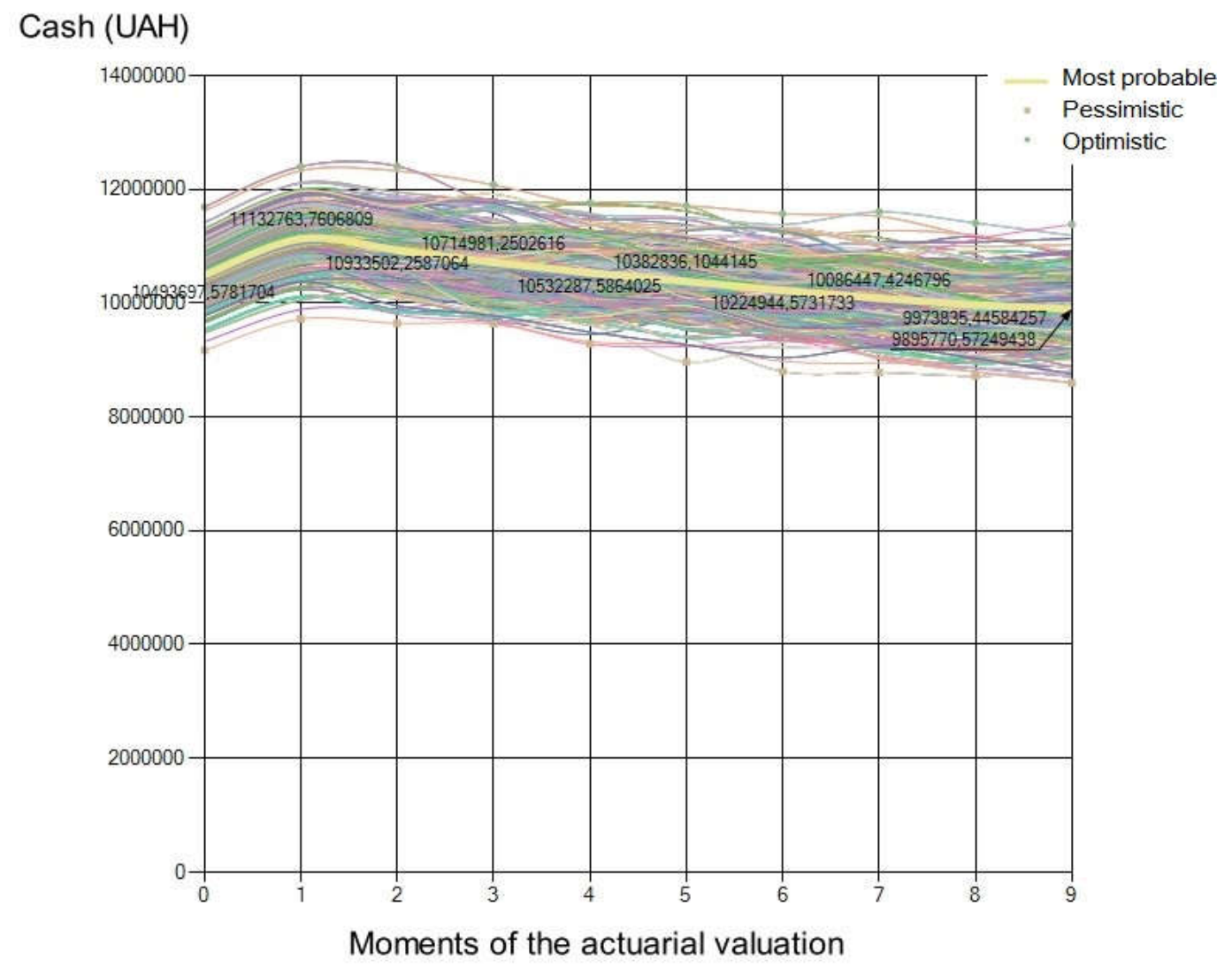

Figure 3 - "Insurance_Life": the results of the insurance fund and insurance events modeling by means of "Insurance_Life" system, 8590 tests (which corresponds to the results in Table 1)

The developed methods, models and modelling system are the basis for the decision support system, which is programmatically implemented and allowed to obtain a number of copyright certificates. "Insurance Life" system architecture, interaction of "Insurance Life" modules with the pCloud service and open source $\mathrm{R}$ functions, used for statistical analysis of the data, given in the Fig.4.

In the first stage, the data on contextual characteristics are processed in the $\mathrm{R}$ package, which allows obtaining the probability of insolvency of insureds $\rho(C)_{Z}$ in each contract. To determine the parameters of logistic regression and to estimate the level of risk, the function of $\mathrm{R}$, in particular GLM, was used. At the same time, we calculate the probability of death of insureds by constructing mortality tables in the "Life Tables building Module". In absence or incompleteness of data, death rates can be modelled using models of population aging dynamics. These data and values the key parameters are loaded into the modelling block "FFPIF modelling Module" that implements the model of the cash flows of the personal insurance fund under conditions of stochastic uncertainty. Numerical simulation results and reports for each module are transmitted to the
"Recommendation Module". Recommendation Module analyzes the results and generates recommendations for ODA.

We consider that the data used to form the contextual characteristics is better to store using cloud data services for faster and more convenient access and the ability to update constantly due to changes in external conditions. Thereby, we suppose to use cloud technology for complex modelling cash flow of insurance fund with constant updating initial information about insured persons and influence factor.

Multiple users can use the cloud storage at the same time, so that the data will be updated efficiently. We managed to implement it by means of cloud-based pCloud service, which supports "Insurance_Life" compatibility by working with two methods of exchanging data through HTTP / JSON and the binary API protocol. The service architecture allows accessing the data at any time regardless of location, and "Insurance_Life" supports fast and secure loading and unloading of data for processing and storage by integrating with the cloud-based pCloud service. The obtained "Insurance_Life" modeling results can also be exported as cloud storage for storage as well as in Microsoft Excel for viewing or further processing. 


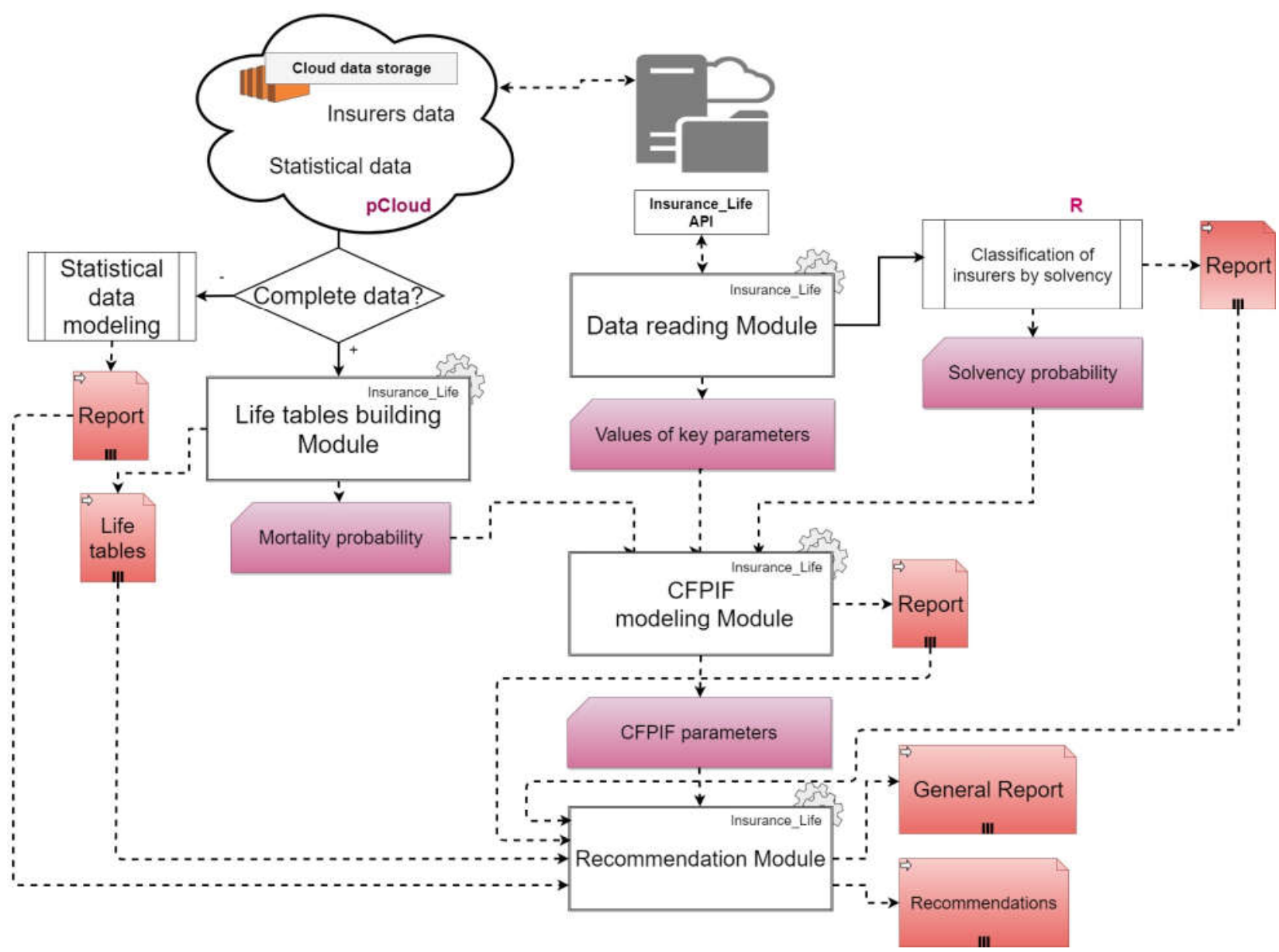

Figure 4 - "Insurance_Life" system architecture, "Insurance_Life" modules interaction with the cloud service pCloud and statistical environment for data processing R, (CFPIF - Cash Flows of the Personal Insurance Fund)

\section{CONCLUSION}

There was developed a model of the cash flow of the personal insurance funds under the conditions of the stochastic uncertainty. This mathematical model differs from the other existing models. It allows taking into account the contextual characteristics of the insured and obtaining not the theoretical value of the concluded contracts, but the adjusted value, that is close to real evaluation (substantiated in table 1-2). The model allows carrying out the complex simulation of the personal insurance fund cash flow with a year sampling interval, considering the external influencing factors. It allows defining the moment of the insurance fund destruction moment and the sum of money, that is a shortage of funds at the moment of destruction (the action or process of causing so much damage to the insurance fund that it no longer exists).

In order to conduct the modelling process, we developed the "Insurance Life" system that supports downloading and uploading data with the cloud service pCloud. Due to the insured's end-to-end encryption of data, that is available from the customer's side, it is impossible to intercept unencrypted data that provides sufficient level of the data security. The practical value of the research is that when analysing and modelling the cash flows of the personal insurance fund flow we came up to the solutions considering the fund development strategy.

\section{REFERENCES}

[1] O.M. Zalyetov, "Policy of insurance protection and strategy of its reform in Ukraine," Bulletin of Taras Shevchenko National University of Kyiv, Economics, Vol. 3, Issue 168, pp. 37-47, 2015. [in Ukrainian].

[2] O.M. Zalyetov, "Socio-economic role of social risks insurance workers in the enterprise," in Proceedings of the Allukrainian Scientific and Practical Conference on Financial mechanisms to ensure economic development of Ukraine in modern conditions, Kiev, Ukrainian, April 15, 2016, pp. 111-113. [in Ukrainian].

[3] O.O. Gamankova, "The concept of the "insurance fund of society" in the modern domestic insurance theory," Finance, accounting and audit, Vol. 17, pp. 51-59, 2011. [in Ukrainian]. 
[4] O.O. Gamankova, V.K. Hlivnyj, "The insurance market in Ukraine in the global insurance area," Finance Ukraine, Vol. 5, pp. 58-67, 2012. [in Ukrainian].

[5] O.O. Gamankova, D.V. Gamankov, O.V. Dymnich, "Theoretical principles of determining the role and place of the state in the insurance market," Finance Ukraine, Vol. 10, pp. 56-73, 2014. [in Ukrainian].

[6] Information System for Insurance Companies, 2017, [Online]. Available: http://www.ins.com. ua/InsCom. [in Russian].

[7] Nexstep Solutions LLC, 2017, [Online]. Available: http://www.ins.com. ua/InsCom. [in Russian].

[8] V.M. Huzhva, "Intelligent decision support systems in insurance: the needs of Ukrainian insurance companies and their satisfaction," Business Inform, Vol. 3, pp. 183-187, 2012. [in Russian].

[9] C.D. Daykin and G.B. Hey, "Managing uncertainty in a general insurance company," Journal of the Institute of Actuaries, Vol. 117, Issue 2, pp. 173-277, 1990.

[10] E.A. Kuzmin, Uncertainty and Certainty in the Management of Organizational and Economic Systems, Monograph, Ekaterinburg: Institute of Economics, 2012, 184 p. [in Russian].

[11] F.H. Knight, Risk, Uncertainty and Profit, Chicago: Houghton Mifflin Company, 1921, $445 \mathrm{p}$.

[12] D. Proske, Catalogue of Risks: Natural, Technical, Social and Health Risks, Springer, 2007, $502 \mathrm{p}$

[13] V.V. Gluschenko, Introduction to Crisis. Financial Crisis. Crisis Management, Monograph, Moscow, 2008, 88 p. [in Russian].

[14] E.S. Venttsel, Operations research. Moscow, 1972, 552 p. [in Russian].

[15] K. Bazylevich, M. Mazorchuk and A. Suhobrus "Determining the probability of insurance policies payments based on a data mining methods," Information Processing Systems, Kharkiv, Vol. 2(139), 2016, pp. 149-155. [in Ukrainian].

[16] L.V. Ivchenko, "The essence of funds: approaches to determine," Global and National Economic Problems, Vol. 13, pp. 798-803, 2016. [in Russian].

[17] C. L. Trowbridge, C. E. Farr, The Theory and Practice of Pension Funding, University of Michigan, 1976, $154 \mathrm{p}$.

[18] A.H. Sholomytskyi, "Financing of funded pensions: actuarial methods and dynamic models," Review of Industrial and Applied Mathematics, Vol. 9, Issue 168, pp. 544-577, 2002. [in Russian].
[19] K. Giannakouris, M. Smihily, Cloud Computing - Statistics on the use by Enterprises, [Online]. Available: http://ec.europa.eu/eurostat/statistics-explained/ index.php/Cloud_computing_-_statistics_on_ the use by enterprises.

[20] Forinsured, New Technologies in Insurance, 2017, [Online]. Available at: http://forinsured. com/news/17/03/06/34983. [in Russian].

[21] Forbes, New Cloud Computing Insurance Attempts to Solve Cloud Liability Concerns For Service Providers, 2013, [Online]. Available at: www.forbes.com/sites/reuvencohen/2013/04/24 /new-cloud-computing-insurance-trys-to-solvecloud-liability-concerns-for-service-providers /\#53893f4e1970. [in Russian].

[22] The operator of cloud technologies De Novo and the company IDC, Results of the annual survey of the market of cloud services in Ukraine, 2017, [Online]. Available at: http://hitech.ua/oblachnyie-servisyi-v-ukraine-itogiissledovaniya. [in Russian].

[23] V.M. Tomashevskiy, Simulation of systems, Kiev, 2005, 352 p. [in Russian].

[24] K. Bazylevich, M. Mazorchuk, "Mathematical models and decision support system for assessing the financial condition of an insurance fund," Bulletin of the Kharkov National University. Math modeling. Information Technology. Automated control systems, Vol. 27, pp. 22-32, 2015. [in Russian].

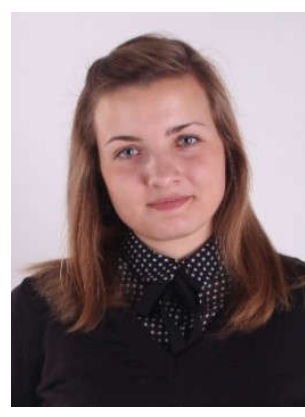

Kseniia Bazilevych is $P h D$ of Information Technologies, Senior Lecturer of the Informatics department at National Aerospace University "Kharkiv Aviation Institute". She graduated with honors from the Faculty of Aircraft Control Systems at National Aerospace University "Kharkiv Aviation Institute", the speciality "Social Informatics" and with a qualification of research scientist (programming sphere). Her fields of scientific activity are databases, analytical and information systems, mobile applications design, intelligent systems for decision support, mathematical modelling. 


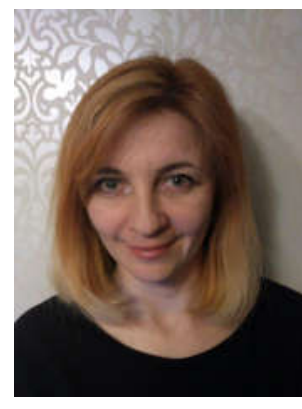

Mariia S. Mazorchuk is PhD of Informational technology, associate professor of the Informatics department at National Aerospace University "Kharkiv Aviation Institute". Master's degree of Information systems. Her scientific and professional interests are statistics, data analytics, Item Response theory, created and development computerized adaptive tests for distance learning.

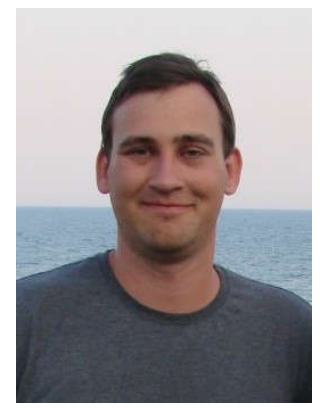

Yurii Parfeniuk is a Master of the Department of Information Systems, at National Technical University "Kharkiv Polytechnic Institute". He graduated from the Computer Information Technologies Faculty, the speciality "Telecommunication systems and networks" and with a qualification of research scientist (telecommunication sphere). His fields of scientific activity are analytical and information systems, distributed systems, logistic systems, software design, mathematical and simulation modeling, fuzzy logic, methods of optimization, control theory.

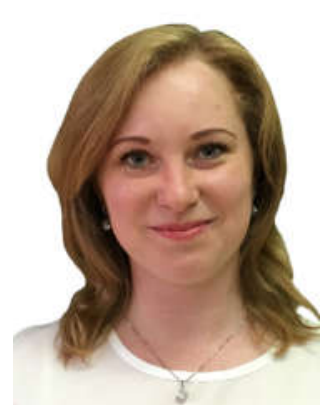

Viktoriia S. Dobriak is $P h D$ of Informational technology, associate professor of the Informatics department at National Aerospace University "KhAl". Master's degree of Applied mathematics. Her scientific and professional interests are statistics, data analytics, Item Response theory, created and development computerized adaptive tests for distance learning.

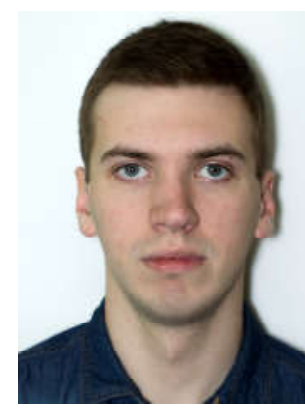

levgen Meniailov is $P h D$ student, assistant of the Informatics department at National Aerospace University "Kharkiv Aviation Institute". He graduated with honors from the Faculty of Aircraft Control Systems at National Aerospace University "Kharkiv Aviation Institute", the speciality "Applied Mathematics". His fields of scientific activity are mathematical modeling, optimization methods, intelligent systems, decision support systems, software design, programming.

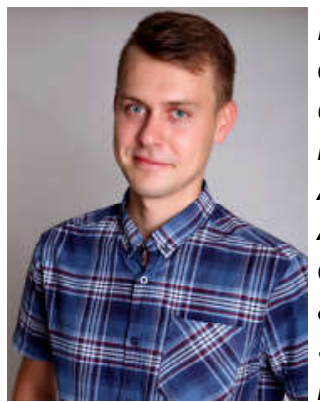

Dmytro Chumachenko is $P h D$ of Artificial Intelligence, associate professor of the Informatics department at National Aerospace University "Kharkiv Aviation Institute". Master's degrees of Social Informatics and Project Management. Scientific and professional interests are simulation, fuzzy

logic, simulation of epidemic processes, agentbased simulation, systems and means of Artificial Intelligence. 